\title{
Seasonality in Abundance, Biomass and Production of the Phytoplankton of Welala and Shesher Wetlands, Lake Tana Sub-Basin (Ethiopia)
}

\author{
Tarekgne Wondmagegne ${ }^{1}$, Ayalew Wondie ${ }^{2}$, Minwyelet Mingist ${ }^{3}$ Jacobus Vijverberg $^{4 *}$ \\ ${ }^{1}$ Department of Animal Science, Debre Markos University, Debre Markos, Ethiopia \\ ${ }^{2}$ Department of Biology, Bahir Dar University, Bahir Dar, Ethiopia \\ ${ }^{3}$ Department of Fisheries, Wetlands and Wildlife Management, Bahir Dar University, Bahir Dar, Ethiopia \\ ${ }^{4}$ Department of Aquatic Ecology, Netherlands Institute of Ecology (NIOO-KNAW), Wageningen, The Netherlands \\ Email: wtarekgne@yahoo.com, ${ }^{*}$ k_vijverberg@yahoo.co.uk
}

Received August 24, 2012; revised September 20, 2012; accepted October 19, 2012

\begin{abstract}
The species composition and production of the phytoplankton community of the Shesher and Welala floodplain Wetlands, on the eastern side of Lake Tana, were studied during four seasons from July 2009 to May 2010. We investigated the spatial and temporal dynamics of phytoplankton, densities, biomass, in relation to physico-chemical conditions. Gross and net primary production was studied at one site in each Wetland. Temperature, dissolved oxygen, conductivity, Secchi-disc depth, nitrate, phosphate and silicate concentrations showed significant temporal variation $(\mathrm{p}<0.05)$, whereas none of these parameters showed significant spatial variation $(p>0.05)$. Thirty six phytoplankton genera/species, belonging to 7 higher taxa were identified. The Chlorophyta dominated the phytoplankton community and contributed $42 \%-53 \%$ of the total observed phytoplankton numbers. Average phytoplankton biomass (chlorophyll $a$ content) over four seasons ranged from $9-121 \mu \mathrm{g} \cdot \mathrm{l}^{-1}$ in Shesher and from $27-206 \mu \mathrm{g} \cdot \mathrm{l}^{-1}$ in Welala, whereas the average gross primary production over three seasons was 10.5 in Shesher and $7.7 \mathrm{mg} \mathrm{O}_{2} \mathrm{I}^{-1} \cdot \mathrm{d}^{-1}$ in Welala. The peak concentration of chlorophyll $a$ was observed in the pre-rainy season, which coincided with a bloom of Microcystis spp. Both Shesher and Welala Wetlands are very productive and have a good water quality but they are threatened by low water inputs since in the summer of 2009 the construction of a dam by local people and facilitated by local officials prevented overflow from Ribb River into the Wetlands. We conclude that the good water quality, the relative high water temperature and high primary productivity make the two Wetlands suitable for culture based fisheries and/or aquaculture, but a wise water resource management is crucially important.
\end{abstract}

Keywords: Biodiversity; Phytoplankton Biomass; Spatial and Temporal Dynamics; Water Resource Management; Wise Use; Fogera Floodplain

\section{Introduction}

Temporal variability in the structure and function of phytoplankton communities is of fundamental importance to the metabolism of an aquatic system [1]. Aquatic environments are subject to high temporal variability, with frequent reorganization of the relative abundance and species composition of phytoplankton as a result of the interactions between physical, chemical and biological variables [2]. In floodplain Wetlands, there are additional factors owing to the hydrodynamic differences arising from the location, morphometry and the main function of a given system. The hydrological cycle, which determines precipitation, governs the flooding extent and the water retention times in the system, generates pulses of ma-

"Corresponding author. terials and nutrients. The study of changes in phytoplankton densities, biomass, species composition and primary production is, therefore, fundamental to the understanding of water quality [3]. Furthermore, fish yields depend on the primary production of phytoplankton, particularly in water bodies in which fish fauna is primarily composed of planktivorous species such as tilapia [4].

A large number of studies have been made on the community structure and primary production of phytoplankton in various East African Lakes and reservoirs [5], however, seasonal floodplain reservoirs were rarely studied. This is also true for Ethiopia.

The Shesher and Welala Wetlands are highly exposed to degradation because of unsustainable farming activities by local farmers such as drainage for recession agriculture [6]. The largest potential threat, however, is a 
huge irrigation project on Ribb River, which is under construction $[7,8]$.

The aim of this study was to assess the water quality and productivity of these two Wetlands in order to evaluate their potential for culture based fisheries. But, this study may also serve as a baseline to investigate to what extent the Wetlands are affected by changes due to the large irrigation project on Ribb River which is now under construction.

\section{Material and Methods}

\subsection{Study-Area}

Lake Tana located at an altitude of $1830 \mathrm{~m}$ is situated on the basaltic Plateau of the north-western highlands of Ethiopia covering an area of ca. $3050 \mathrm{~km}^{2}$. It is the source of the Blue Nile River (Great Abbay), with a catchment area of ca. $16,500 \mathrm{~km}^{2}$. Seven large permanent rivers feed the lake as well as ca. 40 small seasonal rivers. The main tributaries to the lake are Gilgel Abbay (Little Blue Nile), Megech River, Gumara River and the Ribb River. The Blue Nile is the only outflowing river. The shallow lake is Ethiopia's largest lake, containing more than half the country's freshwater resources, and the third largest in the Nile Basin.

Shesher and Welala floodplain Wetlands are located on the eastern side of Lake Tana within Amhara Regional State, South Gondar Zone of Fogera Woreda (Figure 1). The local community gets benefits from these Wetlands in the form of fishing, grazing for cattle and smallscale irrigation. Most of the eastern portions of the Shesher and Welala floodplain Wetlands are cultivated for regression agriculture when the water shifts ("Bahir Shesh") and canals are made for irrigating field crops. Rice farming is important in the area. On the moment ca. $30 \%$ of the land is used for rice cultivation [9].

Shesher and Welala Wetlands are also spawning and nursery habitats for the African Catfish, Clarias gariepinus [10] and they harbor a large diversity of bird species including internationally endangered and threatened ones [6].

The Wetlands are very shallow, maximum depth of Shesher is $1.75 \mathrm{~m}$, whereas the maximum depth of Welala is $2.5 \mathrm{~m}$. Shesher dries up usually during FebruaryMarch and Welala during April or May. In years with much precipitation and much overflow from Ribb River, Welala does not dry up at all [10].

Sufficient water inputs are vital for maintaining an ecological connection with Lake Tana. During the rainy season (July-October), the two Wetlands are charged with overflow from Ribb River, overflow from Lake Tana, overflow from Gumara River, catchment runoff and direct precipitation. Before 2009, overflow from Ribb River was the most important water source [6]. However, during the rainy season of 2009 we observed that the overflow from Ribb River was reduced because of the construction of a dike along the bank of the River constructed by local people and facilitated by local officials to minimize over flooding of the nearby villages (Figure 1).

This research was conducted from July 2009 to May 2010 in four seasons. However, because of the very low water levels during the pre-rainy season it was not possible to measure primary production during this season. There were four sampling sites, two in each Wetland, one in the littoral and one in the open water region of each Wetland. GPS was used to define the sites. Sampling and primary production measurements were carried out between 10:00 am and 3:00 pm when light conditions were generally optimal.

\subsection{Climate}

The mean annual rainfall of the area is ca. $1200 \mathrm{~mm}$ and ranges from 1103 to $1336 \mathrm{~mm}$ and its air temperature ranges from $22^{\circ} \mathrm{C}$ to $29^{\circ} \mathrm{C}$ within years [11]. The climate around L. Tana is characterized by four seasons: 1) A main-rainy season with heavy rains during July-September; 2) A dry season during December-April; 3) A pre-rainy season during May-June and 4) A post-rainy season during October-November. After the main-rainy season, there are the two cropping seasons.
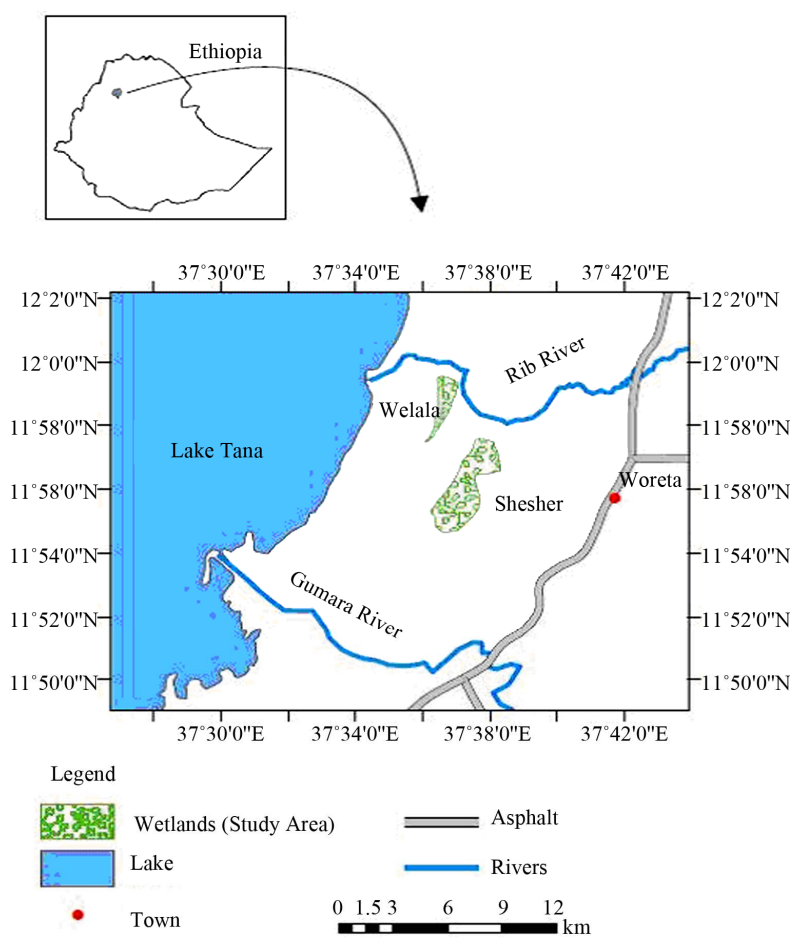

Figure 1. Map of Lake Tana, Ribb River and Gumara River, and associated Shesher and Welala floodplain Wetlands (after [6]). 


\subsection{Physico-Chemical Parameters}

Temperature and dissolved oxygen (DO) were measured with a portable oxymeter probe (OXY-315 WTW 8262), whereas $\mathrm{pH}$, total dissolved solids (TDS) and conductivity were measured simultaneously with the portable probe Syberscan PC 300. Transparency of the pond was measured with a standard Secchi-disc of $20 \mathrm{~cm}$ diameter. Major nutrients (nitrate, phosphate, silicate) were measured using Hach portable spectrophotometer (Hach kit, DR/2010). Nutrient analyses were made from water samples filtered through Whatman $\mathrm{GF} / \mathrm{C}$ filters. Concentrations were measured in the field immediately after collecting the samples.

\subsection{Phytoplankton Sampling}

At each sampling site, the phytoplankton community was sampled with a Van Dorn water sampler at different depths. Subsamples from different depths, representing equal volumes, were pooled. These depth-integrated samples were preserved with lugol solution and $100 \mathrm{ml}$ was allowed to settle in graduate cylinder overnight and the supernatant was siphoned off till $10 \mathrm{ml}$ remained. Of this concentrated sample, $1 \mathrm{ml}$ was used in a Sedgwick-Rafter Cell of which 100 microscopic field were counted for major species according to [12], using an Olympus compound microscope $(100 \times)$. Identification was predominantly based on [13].

\subsection{Chlorophyll $a$ and Primary Production}

Chlorophyll a concentrations were measured once per season in littoral and open water. From each site, 250 $500 \mathrm{ml}$ of the pondwater was filtered through Whatman $\mathrm{GF} / \mathrm{C}$ filters. The filters were folded with alluminium foil, labeled and transported to the laboratory in an ice box which was stored not more than one day. Pigments were grinded and extracted in 90\% acetone. After grinding, the algal material was centrifuged. Then, the extract was decanted into $5 \mathrm{ml}$ cuvette and the absorbance of chlorophyll $a$ was measured spectrophotometrically at wavelengths 665 and $750 \mathrm{~nm}$ before and after acidification. The concentrations were calculated according to [12].

Primary production was measured once per season in the open water zone of each Wetland using the light-dark bottles technique (Winkler's method) with $3 \mathrm{~h}$ incubation during midday (10:30 am - 2:30 pm). Bottles were suspended at a depth of $15-30 \mathrm{~cm}$, measured from the top of the bottle to the water surface. After incubation, the contents were fixed immediately with Winkler's reagents. Thereafter, they were acidified and thoroughly mixed before titration in the laboratory $3-4 \mathrm{~h}$ after collection. Calculations of gross and net photosynthetic rates and respiration rates were done based on the change in oxygen concentration between initial (I), light (L) and dark
(D) bottles. Gross primary productivity $(\mathrm{GPP})=(\mathrm{L}-\mathrm{D}) / 3 \mathrm{~h}$ $=\mathrm{mg} \mathrm{O}_{2} \mathrm{l}^{-1} \cdot \mathrm{h}^{-1}$, net primary productivity $(\mathrm{NPP})=(\mathrm{L}-\mathrm{I}) / 3$ $\mathrm{h}=\mathrm{mg} \mathrm{O} \mathrm{I}^{-1} \cdot \mathrm{h}^{-1}$ and respiration rate $(\mathrm{R})=(\mathrm{I}-\mathrm{D}) / 3 \mathrm{~h}=$ mg $\mathrm{O}_{2} \mathrm{l}^{-1} \cdot \mathrm{h}^{-1}$ [12]. The results were extrapolated into daily production per sampling date using a day length of 10 hrs [14].

\subsection{Data Analysis}

Physico-chemical parameters and phytoplankton composition were measured monthly (eleven sampling dates), chlorophyll $a$ content once per season (four sampling dates) and primary production during 3 seasons only (three sampling dates). At each sampling date, physicochemical parameters, phytoplankton composition and chlorophyll $a$ content were measured at four permanent sites, two in each Wetland, one in the littoral and one in the open water region of each Wetland (four samples per sampling date). Primary production was only measured in the open water region of each Wetland (two samples per sampling date). For data analyses, the SPSS version 16.0 was used [15]. To evaluate the significance of spatial and temporal variations of physico-chemical parameters the Kruskal-Wallis test was performed. Spearman bivariate correlation analysis was done to relate phytoplankton densities to physico-chemical parameters.

\section{Results}

\subsection{Physico-Chemical Parameters}

Within each Wetland physico-chemical parameters did not show significant spatial variation between pelagic and littoral sites (Kruskal Wallis test; $\mathrm{p}>0.05$ ), but temperature, dissolved oxygen, transparency and conductiveity showed significant differences among seasons (Kruskal Wallis test; $\mathrm{p}<0.01$ ) (Table 1). Especially seasonal differences in conductivity were large, whereas dissolved oxygen ranged between 5.1 and 11.4 and $4.4-7.8 \mathrm{mg} \cdot \mathrm{l}^{-1}$ in Shesher and Welala, respectively. Transparency was found to be very low with lowest values during the main rainy season and highest values during the post-rainy season. Average water temperatures varied between $22.0^{\circ} \mathrm{C}$ and $27.2^{\circ} \mathrm{C}$, Welala being slightly warmer than Shesher.

Dissolved nitrate, phosphate and silicate concentrations varied seasonally ( $p<0.05$ ). Generally, concentrations were highest during the main rainy season and low during the post-rainy season (Table 1). During the dry season, phosphate and silicate concentrations were also low, but the nitrate concentration was relatively high, whereas phosphate concentrations reached higher levels in the pre-rainy season.

\subsection{Phytoplankton Composition, Abundance and Seasonality}

A total of 36 genera/species, belonging to 7 taxonomic 
Table 1. Seasonal variation of physico-chemical parameter in Shesher and Welala Wetlands, average \pm 1 SD. Abbreviations used: $\mathrm{MRS}=$ main rainy season, $\mathrm{PORS}=$ post-rainy season, $\mathrm{DS}=$ dry season, $\mathrm{PRS}=$ pre-rainy season, $\mathrm{T}=$ temperature, $\mathrm{DO}=$ dissolved oxygen, TDS = total dissolved solids and SD = standard deviation. Differences are tested between seasons and water bodies (Kruskal Wallis test). Means with identical letters of super scripts indicate a non-significant difference; physical factors $(p \geq 0.01)$, nutrients $(p \geq 0.05)$.

\begin{tabular}{ccccccccc}
\hline & \multicolumn{3}{c}{ Shesher } & \multicolumn{3}{c}{ Welala } \\
\cline { 2 - 8 } & MRS & PORS & DS & PRS & MRS & PORS & DS & PRS \\
\hline $\mathrm{T}\left({ }^{\circ} \mathrm{C}\right)$ & $24.3 \pm 0.32^{\mathrm{b}}$ & $26.8 \pm 0.10^{\mathrm{a}}$ & $22.5 \pm 0.5^{\mathrm{b}}$ & $23.9 \pm 1.3^{\mathrm{b}}$ & $26.7 \pm 0.5^{\mathrm{a}}$ & $25.5 \pm 0.4^{\mathrm{a}}$ & $23.3 \pm 1.3^{\mathrm{b}}$ & $25.5 \pm 0.2^{\mathrm{a}}$ \\
$\mathrm{DO}(\mathrm{mg} / \mathrm{l})$ & $5.2 \pm 0.16^{\mathrm{c}}$ & $7.6 \pm 0.38^{\mathrm{b}}$ & $10.4 \pm 1.0^{\mathrm{a}}$ & $5.8 \pm 0.14^{\mathrm{c}}$ & $6.0 \pm 0.3^{\mathrm{c}}$ & $5.0 \pm 0.1^{\mathrm{c}}$ & $7.6 \pm 0.21^{\mathrm{b}}$ & $4.7 \pm 0.3^{\mathrm{c}}$ \\
Conductivity $(\mu \mathrm{s} / \mathrm{cm})$ & $57.5 \pm 6.45^{\mathrm{d}}$ & $173.3 \pm 10.4^{\mathrm{c}}$ & $247 \pm 6.8^{\mathrm{a}}$ & $249.5 \pm 5.3^{\mathrm{a}}$ & $80.75 \pm 3.0^{\mathrm{d}}$ & $150 \pm 4.1$ & $222.5 \pm 6.5^{\mathrm{b}}$ & $197.3 \pm 0.2^{\mathrm{c}}$ \\
$\mathrm{pH}$ & $6.74 \pm 0.12^{\mathrm{a}}$ & $7.3 \pm 0.10^{\mathrm{a}}$ & $7.23 \pm 0.2^{\mathrm{a}}$ & $8.54 \pm 1.05^{\mathrm{a}}$ & $6.43 \pm 0.3^{\mathrm{a}}$ & $7.02 \pm 0.0^{\mathrm{a}}$ & $7.87 \pm 0.1^{\mathrm{a}}$ & $6.8 \pm 0.3^{\mathrm{a}}$ \\
$\mathrm{TDS}(\mathrm{ppt})$ & $0.02 \pm 0.01^{\mathrm{a}}$ & $0.08 \pm 0.01^{\mathrm{a}}$ & $0.16 \pm 0.03^{\mathrm{a}}$ & $0.12 \pm 0.01^{\mathrm{a}}$ & $0.04 \pm 0.0^{\mathrm{a}}$ & $0.21 \pm 0.3^{\mathrm{a}}$ & $0.14 \pm 0.03^{\mathrm{a}}$ & $0.4 \pm 0.4^{\mathrm{a}}$ \\
$\mathrm{Secchi-disc} \mathrm{depth} \mathrm{(cm)}$ & $3.0 \pm 0.00^{\mathrm{c}}$ & $13.0 \pm 0.41^{\mathrm{a}}$ & $9.50 \pm 0.9^{\mathrm{b}}$ & $8.75 \pm 2.06^{\mathrm{b}}$ & $3.0 \pm 0.00^{\mathrm{c}}$ & $14.0 \pm 0.4^{\mathrm{a}}$ & $10.25 \pm 0.5^{\mathrm{b}}$ & $9.50 \pm 2.7^{\mathrm{b}}$ \\
$\mathrm{NO}_{3}-\mathrm{N}(\mathrm{mg} / \mathrm{l})$ & $3.1 \pm 0.3^{\mathrm{a}}$ & $0.2 \pm 0.0^{\mathrm{d}}$ & $1.26 \pm 0.2^{\mathrm{c}}$ & $0.25 \pm 0.1^{\mathrm{d}}$ & $2.09 \pm 0.6^{\mathrm{b}}$ & $0.16 \pm 0.0^{\mathrm{d}}$ & $1.06 \pm 0.06^{\mathrm{c}}$ & $0.38 \pm 0.03^{\mathrm{d}}$ \\
$\mathrm{PO}_{4}-\mathrm{P}(\mathrm{mg} / \mathrm{l})$ & $0.7 \pm 0.04^{\mathrm{c}}$ & $0.00 \pm 0.0^{\mathrm{g}}$ & $0.2 \pm 0.04^{\mathrm{d}}$ & $0.68 \pm 0.59^{\mathrm{c}}$ & $3.32 \pm 0.6^{\mathrm{a}}$ & $0.16 \pm 0.0^{\mathrm{e}}$ & $0.04 \pm 0.07^{\mathrm{f}}$ & $1.18 \pm 0.12^{\mathrm{b}}$ \\
$\mathrm{SiO}_{2}(\mathrm{mg} / \mathrm{l})$ & $8.5 \pm 0.67^{\mathrm{b}}$ & $0.2 \pm 0.01^{\mathrm{e}}$ & $0.00 \pm 0.0^{\mathrm{f}}$ & $0.55 \pm 0.01^{\mathrm{d}}$ & $19.36 \pm 0.7^{\mathrm{a}}$ & $0.00 \pm 0.0^{\mathrm{f}}$ & $0.00 \pm 0.0^{\mathrm{f}}$ & $0.76 \pm 0.01^{\mathrm{c}}$ \\
\hline
\end{tabular}

groups were observed during the survey (Table 2). In this study, four genera of Cyanophycea (blue green algae), 18 genera of Chlorophyceae (green algae), 10 genera of Bacillariophyceae (diatoms) and Chrysophyceae, Euglenophycea, Desmidiaceae and Dinophyceae with one or two genera were identified. The most diverse and abundant group was Chlorophyceae which contributed $42 \%-53 \%$ of the total assemblage of phytoplankton. Pediastrum spp., Actinastrum spp. and Closterium spp. were the most dominant Chlorophyceae species in Shesher and Closterium spp. and Pediastrum spp. were the most dominant in Welala (Table 2). The second most prominent group was the Cyanophycea, which were dominated by Microcystis spp. in both Wetlands with abundances of ca. $70 \%-95 \%$ in Shesher and Welala (Table 2). In Shesher, the Bacillariophyceae were the third most dominant group, but in Welala the Dinophyceae were more abundant than the Bacillariophyceae. The most abundant diatoms in Shesher were Aulacoseira spp., which accounted for ca. $70 \%$ of the total diatoms (Table 2), but in Welala Cyclotella was the most dominant diatom. Euglenophycea were represented by two genera, Euglena and Phacus, the three other higher taxa by one genus only: Chrysophyceae with Mallomonas, Desmidiaceae with Cosmarium and Dinophyceae with Peridinium (Table 2).

Generally, species diversity and abundance was low in the main rainy season, whereas the highest densities were observed during the pre-rainy season. Both Wetlands showed seasonal variation in species composition. In the pre-rainy season both Wetland were dominated by the same genera, the green algae Closterium and Pediastrum and the blue green alga Microcystis. But, in the main rainy season, Shesher was dominated by the green alga Actinastrum, while Welala was dominated by two green algae, Crucigenia and Eudorina, and the diatom Cyclotella. Also in post-rainy season, different species dominated the phytoplankton community, Pediastrum in Shesher and Microcystis and Peridinium (Dinophyceae) in Welala. In the dry season, Shesher was dominated by the green alga Actinastrum and the diatom Aulacoseira whereas Welala was dominated by two other green algae, Closterium and Pediastrum.

There was a strong negative relationship between densities of blue green algae and nitrate concentration $\left(\mathrm{r}^{2}=\right.$ $-0.842 ; \mathrm{p}<0.001)$ and between diatom densities and silicate concentrations $\left(r^{2}=-0.624 ; p=0.01\right.$; Table 3).

\subsection{Chlorophyll $a$ and Primary Production}

The chlorophyll $a$ concentration in the two Wetlands was within the range between 5.4 and $217.8 \mu \mathrm{g} \cdot \mathrm{l}^{-1}$ and showed marked seasonal variation (Figure 2; p $<0.01$ ). The highest chlorophyll $a$ concentrations were recorded in the pre-rainy season. The mean value of Shesher and Welala were 67.51 and $90.64 \mu \mathrm{g} \cdot \mathrm{l}^{-1}$, respectively. On average chlorophyll $a$ concentrations were higher in Welala (average $91 \mu \mathrm{g} \cdot \mathrm{l}^{-1}$ ) than in Shesher (average $68 \mu \mathrm{g} \cdot \mathrm{l}^{-1}$ ) but differences were not significant $(p=0.36)$. There was no significant relationship between chlorophyll $a$ content and transparency (Secchi-disk depth) in the two Wetlands $\left(\mathrm{r}^{2}=0.12, \mathrm{p}=0.67\right)$.

Gross Primary Productivity (GPP) of Shesher and Welala varied between 1.2 and $19.8 \mathrm{mg} \mathrm{O} \mathrm{I}^{-1} \cdot \mathrm{d}^{-1}$ and showed distinct significant seasonal variation $(\mathrm{p}<0.05)$. The average GPP values in Shesher and Welala were in the same range $\left(5.9-7.6 \mathrm{mg} \mathrm{O}_{2} \mathrm{l}^{-1} \cdot \mathrm{d}^{-1}\right)$. Maximum values were observed in the dry season (January 2010) in both Wetlands. The average Net Primary Productivity (NPP) was $7.7 \mathrm{mg} \mathrm{O}_{2} \mathrm{l}^{-1} \cdot \mathrm{d}^{-1}$ for Shesher and $3.65 \mathrm{mg} \mathrm{O}_{2} \mathrm{l}^{-1} \cdot \mathrm{d}^{-1}$ 
Table 2. Taxa of phytoplankton identified in Shesher and Welala Wetlands and their average abundance (\%) during the study period. Presence/absence in Lake Tana according to [17].

\begin{tabular}{|c|c|c|c|c|}
\hline Taxa & Genera/species & Abundance Shesher (\%) & Abundance Welala (\%) & Presence/Absence Lake Tana \\
\hline \multirow[t]{2}{*}{ Cyanobacteria } & Anabaena sp. & 2.13 & 1.35 & - \\
\hline & Microcystis sp. & 16.01 & 25.35 & + \\
\hline \multirow[t]{2}{*}{ (Cyanophyceae) } & Oscillatoria sp. & 3.55 & 0.11 & - \\
\hline & Phormidium sp. & 1.51 & 0.00 & - \\
\hline \multirow[t]{17}{*}{ Chlorophyceae } & Actinastrum sp. & 13.77 & 3.20 & + \\
\hline & Ankistrodesmus sp. & 1.13 & 0.19 & + \\
\hline & Chlamydomonas sp. & 0.05 & 0.00 & + \\
\hline & Closterium sp. & 5.82 & 20.44 & + \\
\hline & Coelastrum sp. & 0.12 & 0.30 & + \\
\hline & Crucigenia sp. & 0.18 & 3.49 & - \\
\hline & Eudorina sp. & 2.35 & 3.32 & - \\
\hline & Kirchneriella sp. & 1.92 & 0.02 & - \\
\hline & Monoraphidium sp. & 0.12 & 0.10 & + \\
\hline & Oocystis sp. & 0.48 & 0.11 & + \\
\hline & Pandorina sp. & 0.52 & 0.17 & - \\
\hline & Pediastrum sp. & 21.98 & 8.1 & + \\
\hline & Scenedesmus sp. & 1.91 & 0.74 & + \\
\hline & Schroederia sp. & 0.05 & 0.38 & + \\
\hline & Sphaerocystis sp. & 0.00 & 0.69 & + \\
\hline & Staurastrum sp. & 1.81 & 0.77 & + \\
\hline & Volvox sp. & 0.70 & 0.42 & + \\
\hline \multirow[t]{10}{*}{ Bacillariophyceae } & Aulacoseira sp. & 13.86 & 1.92 & + \\
\hline & Cyclotella sp. & 0.83 & 3.73 & - \\
\hline & Cymatopleura sp. & 0.07 & 0.08 & + \\
\hline & Cymbella sp. & 0.00 & 0.35 & + \\
\hline & Navicula sp & 0.82 & 0.22 & - \\
\hline & Nitzschia sp. & 2.93 & 1.09 & + \\
\hline & Pinnularia sp. & 0.02 & 0 & + \\
\hline & Surirella sp. & 0.00 & 0.02 & + \\
\hline & Synedra sp. & 0.46 & 0.43 & + \\
\hline & Tabellaria sp. & 0.06 & 0.02 & + \\
\hline Chrysophyceae & Mallomonas sp. & 0.30 & 0.46 & + \\
\hline Desmidiaceae & Cosmarium sp. & 0.00 & 0.29 & - \\
\hline Dinophyceae & Peridinium sp. & 0.78 & 19.90 & + \\
\hline \multirow[t]{2}{*}{ Euglenophyceae } & Euglena sp. & 3.05 & 1.88 & + \\
\hline & Phacus sp. & 0.69 & 0.33 & + \\
\hline
\end{tabular}


Table 3. Correlation between the concentrations of major nutrients and the densities of major groups of phytoplankton in Shesher and Welala Wetlands. $\mathbf{N}=16$.

\begin{tabular}{cccc}
\hline Nutrients & Phytoplankton taxa & $\mathrm{r}^{2}$ & $\mathrm{p}$-value \\
\hline \multirow{3}{*}{$\mathrm{NO}_{3}-\mathrm{N}$} & Cyanophyceae & -0.842 & 0.000 \\
& Chlorophyceae & 0.047 & 0.862 \\
& Bacillariophyceae & -0.287 & 0.281 \\
$\mathrm{PO}_{4}-\mathrm{P}$ & Cyanophyceae & -0.186 & 0.490 \\
& Chlorophyceae & 0.032 & 0.905 \\
& Bacillariophyceae & -0.471 & 0.065 \\
$\mathrm{SiO}_{2}$ & Cyanophyceae & -0.428 & 0.099 \\
& Chlorophyceae & -0.126 & 0.643 \\
& Bacillariophyceae & -0.624 & 0.010 \\
\hline
\end{tabular}

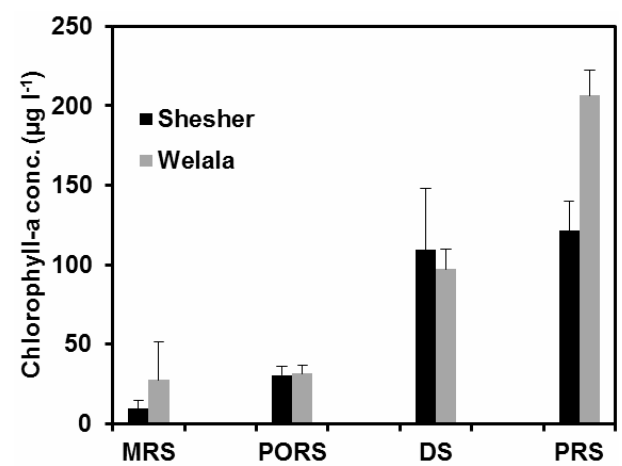

Figure 2. Temporal variation of average chlorophyll $a$ content $\left(\mu \mathrm{g} \cdot \mathrm{l}^{-1}\right)$ in Shesher and Welala Wetlands. Error bars represent +1 SD. Abbreviations used: $\mathrm{MRS}=$ main rainy season, PORS = post-rainy season, $D S=$ dry season, $P R S=$ pre-rainy season.

for Welala and showed the same seasonal pattern as that of GPP (Table 4). There was a strong relationship between GPP and chlorophyll $a$ content $\left(\mathrm{r}^{2}=0.97, \mathrm{p}<\right.$ $0.001)$.

\section{Discussion}

\subsection{Hydrology}

The hydrological conditions during the rainy season of 2009 (our study) were extraordinary because a new constructed dike along the bank of the Ribb River reduced the overflow from Ribb River. As a result, the Wetlands received less water than before. During our study period, direct precipitation was the most important water source, not the overflow from Ribb River as was the case in previous years [6]. Furthermore, one year after our study period, during the rainy period in 2010 , the dike had become less efficient and Ribb River overflow was not substantially reduced [10]. This was very fortunate because a reduced overflow from Ribb River would have led to the drying up and disappearance of these two Wetlands. On the moment cultivation by draining the water through pumping or channeling and flood prevention practices by the local people are the main threats for
Table 4. Summary of gross primary production ( $\Sigma$ GPP), net primary production $(\Sigma \mathrm{NPP})$, respiration $(\Sigma \mathrm{R})$ and gross primary production per unit chlorophyll $(\Sigma \mathrm{GPP} / \mathrm{Chl})$ in three different seasons in Shesher and Welala Wetlands. Abbreviations used: $M R S=$ main-rainy season, PORS = postrainy season, $\mathrm{DS}=$ dry season. Respiration and production in $\mathrm{mg} \mathrm{O}_{2} \mathrm{I}^{-1} \cdot \mathrm{d}^{-1}$, average chlorophyll $a$ content in $\mu \mathrm{g} \cdot \mathrm{l}^{-1}$.

\begin{tabular}{ccccccccc}
\hline \multicolumn{3}{c}{ Shesher } & \multicolumn{7}{c}{ Welala } \\
\hline Season & GPP & NPP & R & GPP/Chl & GPP & NPP & R & GPP/Chl \\
MRS & 1.2 & 0.6 & 0.6 & 0.130 & 1.8 & 0.84 & 0.96 & 0.065 \\
PORS & 1.88 & 0.13 & 1.75 & 0.062 & 2.95 & 1.25 & 1.70 & 0.094 \\
DS & 19.8 & 14.8 & 5.0 & 0.181 & 12.7 & 10.0 & 2.7 & 0.134 \\
\hline
\end{tabular}

these Wetlands [10]. An even larger threat, however, is a huge irrigation project on Ribb River, which is now under construction $[7,8]$. This dam will retain most of the water coming from Ribb watershed during the rainy season. Hence, without mitigating measures these Wetlands will most probably dry up in the near future.

\subsection{Physico-Chemical Parameters}

Physico-chemical parameters did not differ between the two Wetlands (Kruskal Wallis test ( $p>0.05$ ), probably because both Wetlands receive water from the same source, i.e. mainly direct precipitation and catchment runoff. Temperature, dissolved oxygen, conductivity and dissolved nutrients, however, showed significant differences among seasons. In both Wetlands dissolved oxygen levels ranged between 4.7 and $10.4 \mathrm{mg} \cdot \mathrm{l}^{-1}$, which are generally considered favorable for most aquatic organisms [16]. Chlorophyll $a$ showed a weak relationship with water transparency. This was also observed for Lake Tana [14] and implies that water transparency was mainly controlled by the concentrations of suspended sediment particles rather than by phytoplankton. All major nutrients showed relatively high concentration during the rainy season and much lower concentrations during the other seasons. The nutrient concentrations were affected by phytoplankton, which are needed for their growth. Therefore, it is not surprising that dissolved silicate concentration was negatively correlated with diatoms densities and that dissolved nitrate concentrations were negatively correlated with densities of blue green algae. Most probably the dynamics of the nutrients were also influenced by anthropogenic effect, i.e., channelization and farming practices inside both Wetlands.

\subsection{Phytoplankton}

Seven higher taxa and 36 genera/species were identified in the present study. The species compositions of the phytoplankton of Shesher and Welala were similar to that of Lake Tana, but the species richness was much lower than Lake Tana (85 species; [17]). On average green al- 
gae contribute the greatest proportion in terms of numbers (around 50\%) and blue green algae were subdominant (around 25\%), but there were large seasonal differences in densities and species composition. The lowest densities, dominated by several genera of green algae and one diatom, were observed in the main rainy season. This is probably due to the very low water transparency during this period. The highest densities were observed in the dry season and the pre-rainy season. The blue green alga Microcystis became co-dominant in both Wetlands during the post-rainy season, suggesting eutrophic conditions.

\subsection{Chlorophyll a Concentration}

The average chlorophyll $a$ concentrations of Shesher and Welala were 67 and $91 \mu \mathrm{g} \cdot \mathrm{l}^{-1}$, respectively. This is higher than in the Uba and Ruwe floodplain lakes in Tanzania (range: $31-42 \mu \mathrm{g} \cdot 1^{-1}$ ) [18] and much higher than in Lake Tana (average: $4.7 \mu \mathrm{g} \cdot \mathrm{l}^{-1}$ ) [14]. Over the different seasons, chlorophyll $a$ concentrations varied from 9 to 121 $\mu \mathrm{g} \cdot \mathrm{l}^{-1}$ in Shesher and from 27 to $206 \mu \mathrm{g} \cdot \mathrm{l}^{-1}$ in Welala, ranging from eutrophic to hypertrophic conditions. Chlorophyll $a$ concentrations showed a distinct seasonal pattern, low in the main rainy season and a progressive increase in dry and pre-rainy seasons. Such a low algal biomass during periods of heavy rainfall is not unusual and has also been reported for Lake Tana and Lake Victoria $[14,19]$. In both Wetlands, the peak in chlorophyll $a$ concentration was observed in the prerainy season when primary production was stimulated by a relative high water transparency in combination with increased phosphate availability.

\subsection{Primary Production}

In this study, the average gross primary productivity (GPP) of Shesher and Welala Wetlands was in the range of $7-10.5 \mathrm{mg} \mathrm{O}_{2} \mathrm{l}^{-1} \cdot \mathrm{d}^{-1}$. This is high compared with most Ethiopian lakes, Lake Tana (average: $3.4 \mathrm{mg} \cdot \mathrm{O}_{2}$ $\mathrm{l}^{-1} \cdot \mathrm{d}^{-1}$ ) [14] and Lake Kuriftu (average: $4.0 \mathrm{mg} \mathrm{O} \mathrm{l}^{-1} \cdot \mathrm{d}^{-1}$ ) [20]. This might be due to high availability of nutrients which was facilitated by the shallowness of the ponds and by evaporation as a result of which the nutrients became more concentrated.

Primary production showed a distinct seasonal variation, low in the main rainy season and the post rainy season, high in the dry season. The seasonal minimum coincided with a period of heavy precipitation that resulted in land runoff which brought particulate materials into the floodplain Wetlands with consequently reduced the light penetration even though inflow of nutrients were high. GPP was strongly positively correlated with Chlorophyll $a$, but primary production was also limited by light and nutrients. The low gross photosynthetic rate in the main rainy season was caused by the low water transparency. During post-rainy season probably both light and nutrients were limiting production. The maximum GPP in Shesher and Welala in the dry season were not only the result of the high phytoplankton biomass, but also the result of a relatively high GPP per unit of phytoplankton biomass, suggesting less limitation by light and/or nutrients than in the previous two seasons.

\section{Conclusion}

The Welala and Shesher Wetlands are valuable for the local community. They get benefits in the form of fishing, grazing for cattle and small scale irrigation. Furthermore, the Wetlands are spawning and nursery habitats for the African Catfish, C. gariepinus and they harbor a large diversity of bird species. These Wetlands are threatened by unwise farming practices and the construction of huge dam, which will retain most of the water coming from the Ribb River watershed during the rainy season. Mitigating management measures are urgently needed to protect these Wetlands. The water of Shesher and Welala Wetlands is productive, ranging seasonally from eutrophic to hypertrophic. The water quality is suitable for fish and other aquatic organisms. The phytoplankton is generally dominated by Chlorophyceae and diatoms, which are indicators of good water quality and the dissolved oxygen concentrations are high enough to support aquatic life. We conclude that the good water quality, the relative high water temperatures and high water productivity make the Shesher and Welala Wetlands suitable for culture based fisheries and/or aquaculture, but a wise water resource management is crucially important.

\section{Acknowledgements}

The authors would like to thank the Amhara Regional Bureau of Agriculture and Rural Development and South Wollo Zone, Albko Woreda officers and officials, and also IWMI and ARARI for their financial support. We also thank the Staff members of the Bahir Dar Fishery and Other Aquatic Resources Research Center of ARARI as well as from the Bahir Dar University (BDU) Biology and Chemistry Laboratories for their unreserved support of our field and laboratory research. We acknowledge the comments of Dr. Eshete Dejen (FAO, Subregional Office for Eastern Africa) and Mr. Wassie Anteneh (BDU Biology) for useful comments on the manuscript.

\section{REFERENCES}

[1] M. C. Calijuri, A. C. A. Dos Santos and S. Jati, "Temporal Changes in the Phytoplankton Community Structure in a Tropical and Eutrophic Reservoir (Barra Bonita, S.P. Brazil)," Journal of Plankton Research, Vol. 24, 2002, pp. 617-634. doi:10.1093/plankt/24.7.617 
[2] C. S. Reynolds, "Temporal Scales of Variability in Pelagic Environments and the Response of Phytoplankton," Freshwater Biology, Vol. 23, 1990, pp. 25-53. doi:10.1111/j.1365-2427.1990.tb00252.x

[3] W. D. Taylor, E. Kebede and Z. Gebre-Mariam, "Primary and Secondary Production in the Pelagic Zone of Ethiopian Rift Valley Lakes," In: C. Tudorancea and W. D. Taylor, Eds., Ethiopian Rift Valley Lakes, Backhuys Publishers, Leiden, 2002, pp. 95-108.

[4] LFDP-Lake Fisheries Development Project, "Phase II. Final Report," Ministry of Agriculture, Addis Ababa, 1998, pp. 16-20.

[5] J. F. Talling and J. Lemoalle, "Ecological Dynamics of Tropical Inland Waters," Cambridge University Press, Cambridge, 1998.

[6] N. Atnafu, E. Dejen and J. Vijverberg, "Assessment of the Ecological Status and Threats of Welala and Shesher Wetlands, Lake Tana Sub-Basin (Ethiopia)," Journal of Water Resource and Protection, Vol. 3, No. 3, 2011, pp. 540-547. doi:10.4236/jwarp.2011.37064

[7] A. Getahun, E. Dejen and W. Anteneh, "Fishery Studies of Ribb River, Lake Tana Basin, Ethiopia," Ethiopian Nile Irrigation and Drainage Project Coordination Office, Ministry of Water Resources, Final Report E1573, Vol. 2, Addis Ababa, 2008.

[8] T. Alemayehu, M. McCartney and S. Kebede, "The Water Resource Implications of Planned Development in the Lake Tana Catchment, Ethiopia," Ecohydrology and Hydrobiology, Vol. 10, No. 2-4, 2010, pp. 211-222. doi:10.2478/v10104-011-0023-6

[9] N. Atnafu, "Assessment of Ecological and Socio-Economic Importance of Fogera Floodplains: The Case of Welala and Shesher Wetlands," MSc. Thesis, Bahir Dar University, Bahir Dar, 2010.

[10] W. Anteneh, E. Dejen and A. Getahun, "Shesher and Welala Floodplain Wetlands (Lake Tana, Ethiopia): Are They Important Breeding Habitats for Clarias gariepinus and the Migratory Labeobarbus Fish Species?" The Scientific World Journal, Vol. 2012, 2012, Article ID: 298742.
[11] B. Kibret, "In Situ Characterization of Local Chicken Eco-Type for Functional Traits and Production System in Fogera Woreda, Amhara Regional State," MSc. Thesis, Haramaya University, Haramaya, 2008.

[12] R. G. Wetzel and G. E. Likens, "Limnological Analysis," 3rd Edition, Springer, NewDelhi, 2001.

[13] G. W. Prescott, "Algae of the Western Lakes Area," Revised Edition, WMC Brown Company Publishers, Dubuque, 1962.

[14] A. Wondie, S. Mengistu, J. Vijverberg and E. Dejen, "Seasonal Variation in Primary Production of a Large High Altitude Tropical Lake (Lake Tana, Ethiopia): Effects of Nutrient Availability and Water Transparency," Aquatic Ecology, Vol. 41, No. 2, 2007, pp. 195-207. doi:10.1007/s10452-007-9080-8

[15] SPSS for Windows, "Statistical Package for Social Science (SPSS)," Release 13.0, The Apasche Software Foundation, 2007.

[16] US Environmental Protection Agency (USEPA), "The Quality of Our Nation's Water: A Summary of the 1988 National Water Quality Inventory,” EPA Report 440/490-005, Washington DC, 1990.

[17] A. Wondie, "Dynamics of the Major Phytoplankton and Zooplankton Communities and Its Role in the Food Web of Lake Tana, Ethiopia," Ph.D Thesis, Addis Ababa University, Addis Ababa, 2006.

[18] S. M. Ramadhan, "Limnological Studies of Floodplain Lakes Ruwe and Uba, Rufiji River, Tanzania," Institute for Water Education UNESCO-IHE, Delft, 2003.

[19] H. B. O. Lungayia, L. Sitoki and M. Kenyanya, "The Nutrient Enrichment of Lake Victoria (Kenya Waters)," Hydrobiologia, Vol. 458, 2001, pp. 75-82. doi:10.1023/A:1013128027773

[20] Z. Dessalegn, "Temporal Dynamics of Biomass and Primary Production of Phytoplankton in Relation to Some Phsico-Chemical Factors in Lake Koriftu, Ethiopia," MSc. Thesis, Addis Ababa University, Addis Ababa, 2007. 